\title{
Nutraceutical inhibitors of urokinase: Potential applications in prostate cancer prevention and treatment
}

\author{
JERZY JANKUN $^{1,2}$, STEVEN H. SELMAN ${ }^{1,2}$, JACEK ANIOLA ${ }^{3}$ and EWA SKRZYPCZAK-JANKUN ${ }^{1}$ \\ ${ }^{1}$ Medical University of Ohio, Urology Research Center, Department of Urology; \\ ${ }^{2}$ Physiology and Molecular Medicine, Toledo, OH 43614-5807, USA
}

Received February 23, 2006; Accepted March 30, 2006

\begin{abstract}
Epidemiological studies have shown that the clinical incidence of prostate cancer varies by geographical area. When individuals move from low to high prostate cancer incidence areas, the risk of developing cancer increases to the level observed in the indigenous population. It was hypothesized that this observation is related to diet or more specifically to nutraceuticals present in food, medicinal plants, and herbs. Nutraceuticals can inhibit or downregulate enzymes critical for cancer formation. We tested this hypothesis by searching the 3D database of nutraceuticals and docking them to the 3D structure of urokinase. In addition to nutraceuticals, the database contains known uPA inhibitors that served as positive controls. From $>1,000$ compounds, several potential uPA inhibitors have been selected (antipain, leupeptin, folic acid, rosmarinic acid, lavendustin A, fisetin, myricetin, tolfenamic acid). Some of these were subject to further tests on inhibitory activity and inhibition of sprout formation. We found that compounds selected by computational methods indeed inhibit uPA and sprout formation. However, because the database of nutraceuticals was small, we did not expect to find either many or high affinity/specific inhibitors. Rather, we tested this method as a proof of concept. All the facts described above support the hypothesis that nutrients selected by computerized
\end{abstract}

Correspondence to: Dr Jerzy Jankun, Urology Research Center, Medical University of Ohio, Toledo, OH 43614-5807, USA

E-mail: jjankun@meduohio.edu

Present address: ${ }^{3}$ Department of Hygiene and Human Nutrition, A. Cieszkowski University, 31 Wojska Polskiego, Poznan, Poland

Abbreviations: uPA, urokinase plasminogen activator; LMW, low molecular weight; MMP-2, matrix metalloproteinase-2; tPA, tissue plasminogen activator; uPAR, urokinase plasminogen activator receptor; PAI-1, plasminogen activator inhibitor type 1; PSA, prostate specific antigen; B623, benzo(1)thiophene-2-carboxamidine; HUVEC, human umbilical vascular endothelial cells; IPTG, isopropyl B-D-1-thiogalactopyranoside; TIMP-1, tissue inhibitor of metalloproteinase-1

Key words: urokinase, nutraceuticals, cancer, angiogenesis searches can inhibit unwanted uPA activity and thus reduce angiogenesis. If true, a proper diet rich in uPA-inhibiting nutraceuticals might support the prevention of prostrate cancer and be a supportive tool in prostate cancer treatment.

\section{Introduction}

Prostate cancer is the second most common cause of cancerrelated death among American men. The widespread use of the PSA test as an adjunct to digital rectal examination has led to an increase in the diagnosis of prostate cancer in its early stages. Treatment of organ confined prostatic cancer includes radical prostatectomy, radiotherapy, cryosurgical ablation and watchful waiting. Results from all these are favorable at least in terms of short-term outcomes. Still, $30 \%$ of patients with T1c disease will experience biochemical failure within 5 years of treatment. All forms of treatment carry morbidity and alternative methods of treatment or prevention are being pursued, among them, life style changes such as alteration in $\operatorname{diet}(1)$.

Epidemiological studies have shown that the clinical incidence of prostate cancer varies by geographical area. When individuals move from low to high prostate cancer incidence areas, the risk of developing cancer increases to the level observed in the indigenous population. It was hypothesized that this observation is related to diet or more specifically to nutraceuticals present in fruits, vegetables, common beverages, grains, marine products, medicinal plants, and herbs. Rafi et al defines nutraceuticals as naturally derived, bioactive compounds that have health-promoting, disease-preventing, or medicinal properties and have an impact on human genes or proteins that control cellular metabolisms (2). Two prominent nutraceuticals (curcumin and EGCG from green tea) have been implicated in anti-cancer activity (3). However, numerous pathways have been postulated and the mechanism of action remains unclear. Examples include inhibition of COXs, LOX, uPA, nuclear factor- $\kappa \mathrm{B}$ activity, and downregulating the antiapoptotic protein, Bcl-2 (4-9). Also, the same chemical might cause the same biological effect, but by different pathways. It has been reported that curcumin down-regulates MMP-2 $(10,11)$, inhibits P-12-LOX and reduces the production of 12HETE, which leads to downregulation of VEGF $(7,12,13)$. Inhibiting any of these enzymes alone would reduce angiogenesis. Targeting diverse proteins by the same nutraceutical seems to be the rule rather than the exception. 
Moreover, the binding affinity of ligands to their enzymes can be species-specific. For example, a direct comparison of human and murine neutrophil elastase and proteinase 3 revealed significant differences among species in physicochemical properties, substrate specificities and enzyme kinetics towards synthetic peptide substrates, oxidized insulin B chain, and fibri-nogen (14). Also, there are significant structural differences between human and animal enzymatic targets as we detected in the case of urokinase (15). Rat uPA turned out to be the most distant to human uPA, while the structure of baboon and mouse uPA are surprisingly very similar to human uPA. Thus, extra-polation of epidemiological results from human study and attempts to confirm them in an animal model can be confusing. Also, efforts to identify a single enzyme as a target for nutra-ceuticals deduced from human study (inhibition of VEGF in angiogenesis as an example) can miss other critical targets. The alternative is to check numerous enzymes for inhibitory activity of nutraceuticals to predict the simultaneously occurring events and competition between them. However, the search for uPA inhibitors from hundreds of thousands of nutraceuticals using classical biochemical methods is not practical. A more acceptable method is a computerized search of enzyme inhibitors using in silico selection from a database of nutraceuticals and $3 \mathrm{D}$ structures of proteins to narrow down the number of molecules worth pursuing. In this study, we attempted to verify this concept using a small database of nutraceuticals to find enzyme inhibitors for the urokinase plasminogen activator.

Urokinase (a serine protease) is one of the important enzymes in prostate cancer formation that is overexpressed in prostate carcinomas and also in many other cancers (16). The cancer promoting properties of this enzyme are caused by the activation of cancer proteolytic machinery, and the hydrolysis of basement membrane and connective tissue proteins. It has been reported that cells transfected with a plasmid, causing an overexpression of uPA in prostate cancer cells, showed a marked increase in metastasis, compared to the parental cell phenotype in the animal model. Moreover, when uPA was inhibited, a reduction of metastatic potential was shown in many in vitro and in vivo models (17-19).

It has also been shown that inhibitors of uPA can reduce tumor size. Billstrom et al showed that p-aminobenzamidine, a competitive inhibitor of uPA, caused dose-dependent inhibition of uPA activity and decreased tumor-growth in DU-145 (human prostate cancer cells) inoculated SCID mice, when compared with non-treated animals (20). Amiloride, another uPA inhibitor, reduces tumor growth and decreases the proliferation of the tumor cells in hepatomas, intestinal carcinomas and LnCAP prostatic cancer xenografts grown in SCID mice $(21,22)$.

This phenomenon is related to angiogenesis. The tips of neovascular advancing capillary vessels surrounding tumors have been reported to contain high amounts of uPA and its receptor. The binding of the proteolytically inactive ligand to the UPA receptor reduces the amount of uPA on the surface of capillary endothelial cells, reducing angiogenesis and consequently tumor growth (23). Also, our studies have shown that uPA inhibitors reduce angiogenesis in the chick embryo model and reduce the length and number of sprouts in a human umbilical vascular endothelial cells (HUVEC) assay. In both cases, inhibition of uPA activity on the tip of the capillary vessel or sprout prohibits cell migration and reduces their growth $(22,24)$. Thus, inhibition of uPA can reduce tumor size, angiogenesis and metastasis, which we hope can be regulated by nutraceuticals inhibiting uPA.

\section{Materials and methods}

Obtaining the starting structure. All molecular modeling, structure visualization and database creation were done on an SGI workstation using the Insight II package ver. 2000 from Accelrys, Inc., San Diego, CA and the Sybyl program ver. 6.8 from Tripos, Inc., St. Louis, MO. Further visualization was done on a PC using Deep View Swiss-Protein PDBViewer and its PovRay extension (25) or the PyMOL program version 0.98, and ABPS tools (26). The atomic coordinates of uPA were retrieved from the Protein Data Bank, entry 1LMW, depicting the structure of the catalytic domain of human uPA with the inhibitor Glu-Gly-Arg chloromethyl ketone (27). To prepare a target structure of uPA for calculations, the inhibitor was removed from the set of coordinates, hydrogen atoms were added, and the appropriate charges were assigned throughout the molecule assuming a physiological $\mathrm{pH}$ 7.4. The partial and formal charges were assigned accordingly to the extensible systemic force field (esff).

Three-dimensional database of the chemical structures of nutrients. Compounds of nutrients randomly selected from literature were drawn using the ISIS/Draw computer program from MDL Information Systems. Each structure was copied into the ISIS/Base program with all additional information (food source, common name, full name, known activities and references) forming a fully searchable database.

Subsequently, 2D structures were converted into 3D structures needed for docking calculations using the Genfra in Insight II. During this conversion, compounds with a known chirality were introduced as they were reported to protect their current configuration. If the chiral center was detected, but not specified, the program produced all isomers for up to six chiral centers, producing up to $2^{6}=64$ possible isomers. Therefore, the actual number of 3D structures is usually much higher than the number of $2 \mathrm{D}$ entries in the database (in our database $2 \mathrm{D}=1065,3 \mathrm{D}=2079$ ).

Ligand search program. This program analyzes the geometrical fit of given chemicals into the binding site and calculates other determinants of good binding such as hydrogen bonds, lipophilic, ionic, and acyclic interactions. Scoring functions statistically evaluate the fit of all potential ligands.

$$
\text { Score }=-73.33 \mathrm{~mol} / \mathrm{kcal} \Delta \mathrm{G}
$$

where: $\Delta \mathrm{G}=\Delta \mathrm{G}_{\mathrm{o}}+\Delta \mathrm{G}_{h b} f(\Delta \mathrm{R}) f(\Delta \alpha)+\Delta \mathrm{G}_{i o n} f(\Delta \mathrm{R}) f(\Delta \alpha)+$ $\Delta \mathrm{G}_{\text {lipo }} \mathrm{A}_{\text {lipo }}+\Delta \mathrm{G}_{r o t} \mathrm{NR} \Delta \mathrm{G}$;

$\Delta \mathrm{G}_{\mathrm{o}}$ represents the contribution to the binding energy that does not directly depend on any specific interactions with the receptor; $\Delta \mathrm{G}_{h b}$ and $\Delta \mathrm{G}_{i o n}$ represent the contribution from an ideal hydrogen bond and unperturbed ionic interactions, 
Table I. Properties of selected nutraceuticals.

\begin{tabular}{|c|c|c|c|}
\hline Name & Structure & Calculated score & $\mathrm{IC}_{50}$ \\
\hline Antipain & $\begin{array}{l}\text { [(S)-1-Carboxy-2-Phenyl]-carbamoyl-Arg-Val- } \\
\text { arginal }\end{array}$ & $-33.7 \mathrm{kcal} / \mathrm{mol}$ & $17 \pm 6 \mathrm{mM}$ \\
\hline Leupeptin & Ac-Leu-Leu-argininal & $-32.6 \mathrm{kcal} / \mathrm{mol}$ & $28 \pm 7 \mathrm{mM}$ \\
\hline Folic acid & & $-31.5 \mathrm{k} \mathrm{cal} / \mathrm{mol}$ & $21 \pm 6 \mathrm{mM}$ \\
\hline $\begin{array}{l}\text { Rosmarinic } \\
\text { acid }\end{array}$ & & $-31.0 \mathrm{kcal} / \mathrm{mol}$ & $28+9 \mathrm{mM}$ \\
\hline Lavendustin $\mathrm{A}$ & & $-30.2 \mathrm{kcal} / \mathrm{mol}$ & ND \\
\hline Fisetin & & $-28.0 \mathrm{kcal} / \mathrm{mol}$ & ND \\
\hline Myricetin & & $-27.4 \mathrm{kcal} / \mathrm{mol}$ & ND \\
\hline $\begin{array}{l}\text { Tolfenamic } \\
\text { acid }\end{array}$ & & $-27.3 \mathrm{kcal} / \mathrm{mol}$ & ND \\
\hline
\end{tabular}

respectively; $\Delta \mathrm{G}_{\text {lipo }}$ represents the contribution from lipophilic interactions, which is proportional to the lipophilic surface $\mathrm{A}_{\text {lipo }} ; \Delta \mathrm{G}_{\text {rot }}$ represents the contribution due to freezing of internal degrees of freedom in the fragment; NR is the number of acyclic bonds; $\Delta \mathrm{R}$ is the deviation of $\mathrm{H} \rightarrow \mathrm{A}$ bond length from the ideal value of $1.9 \AA \mathrm{A} ; \Delta \alpha$ is the deviation of the hydrogen bond angle from the ideal value of $180^{\circ}$. In general, a lower score represents a higher affinity and stronger binding of a ligand to the receptor (Insight II ver. 2000 and Sybyl ver. 6.8). 


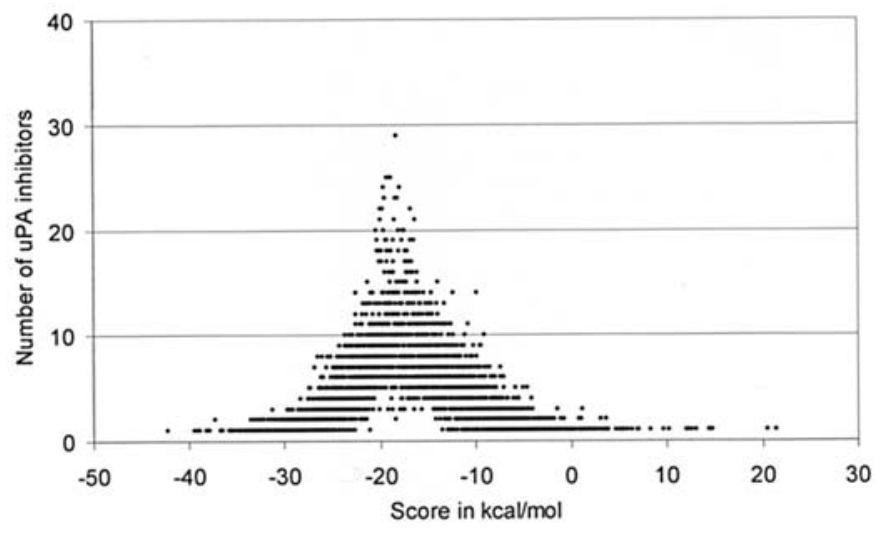

Figure 1. Score distribution for $>2,000$ nutraceutical 3D structures. The best uPA inhibitors are compounds with the lowest score.
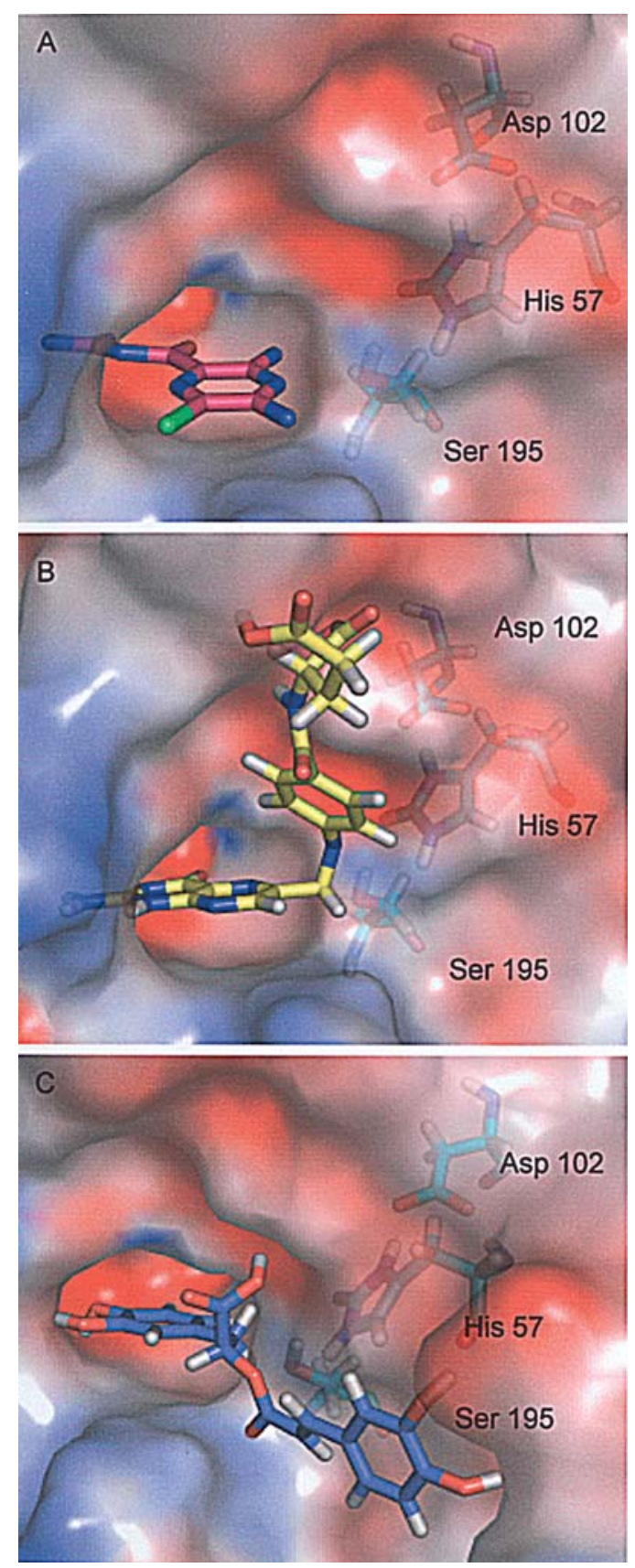

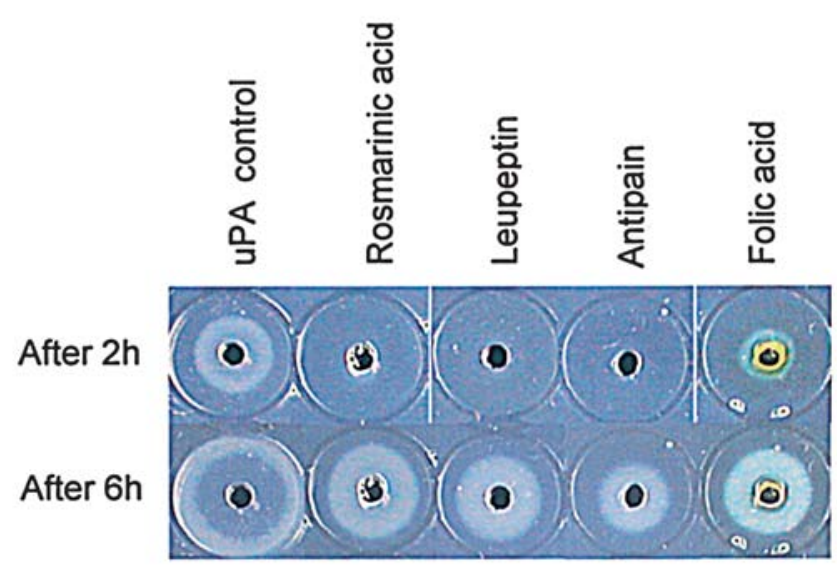

Figure 3. Inhibition of uPA activity by different nutraceuticals as measured by zymography. Plasmin activated by uPA hydrolyzes casein, which is manifested on clear gel as opaque zones, which become clear again as time progresses. uPA activity is directly proportional to the radius of the lysed zone.

Assay of urokinase plasminogen activator activity (zymography). The assay was done by zymography, essentially as described before and modified by us to quantify uPA activity (28). Briefly, $20 \mathrm{ml}$ of casein solution $(100 \mathrm{mg} / \mathrm{ml})$ in PBS is mixed with $50 \mathrm{ml}$ of $1.56 \%$ of agarose in PBS at $50^{\circ} \mathrm{C}$ containing 2 Sigma units of plasminogen (from Sigma). The mixture was poured into a $8.5 \times 12.8 \mathrm{~cm}$ mold and spread evenly. After the gel hardened, two $1.8 \mathrm{~mm}$ holes were made. The holes were filled with $2.5 \mu \mathrm{l}$ of uPA (from American Diagnostica Inc., Stamford, CT) or uPA/inhibitor mixture. The gel was incubated at $37^{\circ} \mathrm{C}$ for $6 \mathrm{~h}$. Diffusing uPA into the gel activates plasminogen to plasmin, which hydrolyzes casein producing characteristic lysis zones. The level of uPA activity was determined from the radius of the lysis zones. The inhibitory activities of nutrients toward urokinase are inversely proportional to the radius of the lysed zones. The series dilution of uPA provided a standardization on each gel. Based on the uPA standard curve of activity, we determined the $\mathrm{IC}_{50}$ for these inhibitors.

Sprout formation assay. The uPA inhibitors were tested on their ability to inhibit angiogenesis using human endothelial cells as a model. These cells express a high activity of uPA on the tip of the sprout when grown in fibrin gels. Inhibition of uPA prevents sprout formation and is a measure of antiangiogenic activity.

HUVEC cells were grown to confluence in EGM-2 growth medium. Next, the cells were trypsinized and seeded onto $0.5 \%$ agarose-coated culture dishes. This procedure resulted in cell aggregate formation after $24 \mathrm{~h}$ of incubation at $37^{\circ} \mathrm{C}$.

Figure 2. Semitransparent surface of uPA colored by charges: negatively charged in red (-5) and positively charged in blue $(+5)$. Charges were calculated using the ABPS tool of PyMOL. For clarity, only the amino acids of the catalytic triad are indicated on all models (His 57, Asp 102, Ser 195). (A) Calculated by the docking position of amiloride inside of the specificity pocket formed by amino acids $187-197 ; 212-229$. Amiloride is in a very similar position as in the X-ray structure (1F5L) with $r s m d=0.88 \AA$; (B) The calculated position of folic acid and (C) rosmarinic acid. 
The HUVEC aggregates were decanted by allowing the cells to stand for $30 \mathrm{~min}$ at room temperature. The old-medium supernatant was decanted and HUVEC aggregates were suspended in $5 \mathrm{ml}$ of fresh EGM-2 growth medium.

Three-dimensional fibrin gels were prepared by mixing the following solution in 12-well culture plates: $960 \mu 1$ of human fibrinogen (Type III, $60 \%$ of protein clotable; $2.50 \mathrm{mg} /$ ml concentration in RPMI-1640 medium), $40 \mu 1$ of HUVEC aggregate suspension, and $12.5 \mu 1$ of human thrombin (25 IU/ $\mathrm{ml}$ concentration in RPMI-1640 medium). The sprout formation assay was done basically as described by Pepper et al (29). Briefly, the HUVEC aggregates were suspended in fibrin gel containing uPA inhibitors; $1 \mathrm{ml}$ of EGM-2 growth medium was later added over the fibrin gel. The mixture was gently mixed and allowed to gel for $\sim 4 \mathrm{~min}$ at $37^{\circ} \mathrm{C}$ before adding EGM-2 growth medium over the gel. After 3 days of cell incubation, cultures were fixed in situ for $24 \mathrm{~h}$ with $2 \mathrm{ml}$ of $10 \%$ formalin solution and photographed under a phasecontrast microscope.

\section{Results and Discussion}

The docking approach supported by empirical scoring functions has been used successfully in the past to identify protein ligands by several computational methods (30-36). It has been reported that the best results were obtained for the subset of 16 serine protease complexes with a standard deviation of $1.0 \log \mathrm{K}_{\mathrm{i}}$ unit and an $\mathrm{R}^{2}$ value of $0.86 \AA$ (37). This approach of searching for novel inhibitors is especially attractive for urokinase, since uPA is a serine protease.

As shown in Fig. 1, a computer search for uPA inhibitors revealed several compounds with a high score $(-43$ to $-27 \mathrm{kcal} /$ mol). The best scoring compounds were pterins, which are uncommon in the popular diet (38), not commercially available, and of very poor water solubility. As shown in Table I, other examples of selected compounds include: antipain, leupeptin, folic acid, rosmarinic acid, lavendustin A, fisetin, myricetin, and tolfenamic acid. Some of these were not available commercially. Therefore, the final selection included only commercially available, good uPA inhibitors: antipain, leupeptin, folic acid, and rosmarinic acid.

Docking calculations revealed that most of the inhibitors where inserted into the specificity pocket formed by amino acids 187-197 and 212-229 of uPA, which block the recognition site, preventing binding of uPA with its substrate plasmin. This is the case with inhibition of uPA by small molecules such as benzamidine, p-benzamidine, and amiloride (39). With bigger molecules, such as folic acid or rosmarinic acid, only part of the molecule was in that negatively charged pocket, while the remaining part hovers close to the catalytic triad $(57,102,195)$ providing additional steric hindrance to uPA interactions with its substrates (Fig. 2).

Some nutraceuticals create an additional challenge in measuring uPA activity because their intense light absorption in wavelength used in UPA spectroscopic activity determination. Hence, we used zymography, which is considered a semi-quantitative method of uPA activity determination. We modified this assay by introducing standardization (the radius of lysed zones vs. uPA activity) and quantifying uPA activity. The inhibitory activities of selected nutraceuticals toward urokinase measured by zymography were inversely proportional to the radius of the lysed zones on the gel. Based on the standard curve of uPA activity done with every assay, we determined the $\mathrm{IC}_{50}$ for these inhibitors; rosmarinic acid $\mathrm{IC}_{50}=28 \mathrm{mM}$; leupeptin $\mathrm{IC}_{50}=28 \mathrm{mM}$; antipain $\mathrm{IC}_{50}=17 \mathrm{mM}$; folic acid $\mathrm{IC}_{50}=21 \mathrm{mM}$. Two of these nutraceuticals (antipain, leupeptin) are known serine protease inhibitors (40). However, there is no information available on that type of inhibitory activity for folic or rosmarinic acids (Fig. 3).

For the sprout formation assay, we have chosen three uPA inhibitors, omitting folic acid, since at uPA inhibitory concentration it produces an intense yellow color in the gel, which makes it difficult to determine the length and number of sprouts. In these three uPA inhibitors for which the sprout formation was measured, two distinct patterns were observed. First, for leupeptin, we have found that $50 \%$ inhibition of the number and length of sprouts was observed at a concentration of $24 \mathrm{mM}$, which was very close to urokinase inhibition at $\mathrm{IC}_{50}(28 \mathrm{mM})$. This observation strongly suggests that observed inhibition of sprout formation was caused by inhibition of uPA. Second, in the case of rosmarinic acid and antipain, inhibition of sprout formation was observed at much lower concentrations than the $\mathrm{IC}_{50}$ of uPA (for rosmarinic acid $<0.84 \mathrm{mM}$ and for antipain $<1.06 \mathrm{mM}$ ). These values are well below the $\mathrm{IC}_{50}$ of $\mathrm{uPA}$. We concluded that in addition to inhibition of sprout formation by uPA inhibitors, some other mechanisms were involved. Huang and Zheng reported the reduction of angiogenesis by rosmarinic acid at a concentration of $0.2 \mathrm{mM}$. They attributed the anti-angiogenic potential of rosmarinic acid to its anti-oxidative activity, which further resulted in the inhibition of reactive oxygen species associated VEGF expression and IL-8 release (41).

Because the database of nutraceuticals was small, we did not expect to find either many or high affinity/specific inhibitors. Rather, we tested this method as a proof of concept. All the facts described above support the hypothesis that nutrients selected by computerized searches can inhibit unwanted uPA activity and thus reduce angiogenesis. If true, a proper diet rich in uPA-inhibiting nutraceuticals might support the prevention of prostrate cancer and be a supportive tool in prostate cancer treatment.

\section{Acknowledgements}

This work was supported in part by grants from: NIH: CA90524, CA109625; and the Frank D. Stranahan Endowment Fund for Oncological Research. J.J. and E.S.J thank Dr R. Hart (the President of American Diagnostica Inc., Stamford, CT, USA) for his support and the chemicals used in this study. We acknowledge the technical assistance of Ms. Maria Szkudlarek.

\section{References}

1. Achbarou A, Kaiser S, Tremblay G, Ste-Marie LG, Brodt P, Goltzman D and Rabbani SA: Urokinase overproduction results in increased skeletal metastasis by prostate cancer cells in vivo. Cancer Res 54: 2372-2377, 1994.

2. Rafi MM: Elucidating the role of nutraceuticals in overexpressing antiapoptotic proteins in prostate cancer. Nutrition 20: $78-82,2004$ 
3. Manson MM, Farmer PB, Gescher A and Steward WP: Innovative agents in cancer prevention. Recent Results Cancer Res 166: 257-275, 2005.

4. Chung LY, Cheung TC, Kong SK, Fung KP, Choy YM, Chan ZY and Kwok TT: Induction of apoptosis by green tea catechins in human prostate cancer DU145 cells. Life Sci 68: 1207-1214, 2001.

5. Gao X, Grignon DJ, Chbihi T, Zacharek A, Chen YQ, Sakr W, Porter AT, Crissman JD, Pontes JE, Powell IJ, et al: Elevated 12-lipoxygenase mRNA expression correlates with advanced stage and poor differentiation of human prostate cancer. Urology 46: 227-237, 1995 .

6. Honn KV, Timar J, Rozhin J, Bazaz R, Sameni M, Ziegler G and Sloane BF: A lipoxygenase metabolite, 12-(S)-HETE, stimulates protein kinase C-mediated release of cathepsin B from malignant cells. Exp Cell Res 214: 120-130, 1994.

7. Miocinovic R, McCabe NP, Keck RW, Jankun J, Hampton JA and Selman SH: In vivo and in vitro effect of baicalein on human prostate cancer cells. Int J Oncol 26: 241-246, 2005.

8. Skrzypczak-Jankun E, McCabe NP, Selman SH and Jankun J: Curcumin inhibits lipoxygenase by binding to its central cavity: theoretical and X-ray evidence. Int J Mol Med 6: 521-526, 2000.

9. Skrzypczak-Jankun E, Zhou K and Jankun J: Inhibition of lipoxygenase by (-)-epigallocatechin gallate: X-ray analysis at $2.1 \mathrm{~A}$ reveals degradation of EGCG and shows soybean LOX-3 complex with EGC instead. Int J Mol Med 12: 415-420, 2003.

10. Shao ZM, Shen ZZ, Liu CH, Sartippour MR, Go VL, Heber D and Nguyen M: Curcumin exerts multiple suppressive effects on human breast carcinoma cells. Int J Cancer 98: 234-240, 2002.

11. Gururaj AE, Belakavadi M, Venkatesh DA, Marme D and Salimath BP: Molecular mechanisms of anti-angiogenic effect of curcumin. Biochem Biophys Res Commun 297: 934-942, 2002.

12. Arbiser JL, Klauber N, Rohan R, van Leeuwen R, Huang MT, Fisher C, Flynn E and Byers HR: Curcumin is an in vivo inhibitor of angiogenesis. Mol Med 4: 376-383, 1998.

13. McCabe NP, Selman SH and Jankun J: Vascular endothelial growth factor production in human prostate cancer cells is stimulated by overexpression of platelet 12-lipoxygenase. Prostate (In press).

14. Wiesner O, Litwiller RD, Hummel AM, Viss MA, McDonald CJ, Jenne DE, Fass DN and Specks U: Differences between human proteinase 3 and neutrophil elastase and their murine homologues are relevant for murine model experiments. FEBS Lett 579: 5305-5312, 2005.

15. Jankun J and Skrzypczak-Jankun E: Binding site of amiloride to urokinase plasminogen activator depends on species. Int J Mol Med 8: 365-371, 2001.

16. Conese $\mathrm{M}$ and Blasi F: The urokinase/urokinase-receptor system and cancer invasion. Baillieres Clin Haematol 8: 365-389, 1995.

17. Rabbani SA, Harakidas P, Davidson DJ, Henkin J and Mazar AP: Prevention of prostate-cancer metastasis in vivo by a novel synthetic inhibitor of urokinase-type plasminogen activator (uPA). Int J Cancer 63: 840-845, 1995.

18. Dano K, Romer J, Nielsen BS, Bjorn S, Pyke C, Rygaard J and Lund LR: Cancer invasion and tissue remodeling - cooperation of protease systems and cell types. APMIS 107: 120-127, 1999.

19. Duffy MJ: Proteases as prognostic markers in cancer. Clin Cancer Res 2: 613-618, 1996.

20. Billstrom A, Hartley-Asp B, Lecander I, Batra S and Astedt B: The urokinase inhibitor p-aminobenzamidine inhibits growth of a human prostate tumor in SCID mice. Int J Cancer 61: 542-547, 1995.

21. Koo JY, Parekh D, Townsend CM Jr, Saydjari R, Evers BM, Farre A, Ishizuka J and Thompson JC: Amiloride inhibits the growth of human colon cancer cells in vitro. Surg Oncol 1: 385-389, 1992 .
22. Jankun J, Keck RW, Skrzypczak-Jankun E and Swiercz R: Inhibitors of urokinase reduce size of prostate cancer xenografts in severe combined immunodeficient mice. Cancer Res 57: 559-563, 1997.

23. Pepper MS, Sappino AP, Stocklin R, Montesano R, Orci L and Vassalli JD: Upregulation of urokinase receptor expression on migrating endothelial cells. J Cell Biol 122: 673-684, 1993.

24. Swiercz R, Keck RW, Skrzypczak-Jankun E, Selman SH and Jankun J: Recombinant PAI-1 inhibits angiogenesis and reduces size of LNCaP prostate cancer xenografts in SCID mice. Oncol Rep 8: 463-470, 2001.

25. Guex N and Peitsch MC: Swiss-Model and the Swiss-PdbViewer: an environment for comparative protein modeling. Electrophoresis 18: 2714-2723, 1997.

26. Baker NA, Sept D, Joseph S, Holst MJ and McCammon JA: Electrostatics of nanosystems: application to microtubules and the ribosome. Proc Natl Acad Sci USA 18: 10037-10041, 2001.

27. Spraggon G, Phillips C, Nowak UK, Ponting CP, Saunders D, Dobson CM, Stuart DI and Jones EY: The crystal structure of the catalytic domain of human urokinase-type plasminogen activator. Structure 3: 681-691, 1995.

28. Jankun J, Maher VM and McCormick JJ: Malignant transformation of human fibroblasts correlates with increased activity of receptor-bound plasminogen activator. Cancer Res 51: 1221-1226, 1991.

29. Pepper MS, Montesano R, Vassalli JD and Orci L: Chondrocytes inhibit endothelial sprout formation in vitro: evidence for involvement of a transforming growth factor-beta. J Cell Physiol 146: 170-179, 1991.

30. Glen RC and Allen SC: Ligand-protein docking: cancer research at the interface between biology and chemistry. Curr Med Chem 10: 763-767, 2003.

31. Gschwend DA, Good AC and Kuntz ID: Molecular docking towards drug discovery. J Mol Recognit 9: 175-186, 1996.

32. Honer C, Nam K, Fink C, Marshall P, Ksander G, Chatelain RE, Cornell W, Steele R, Schweitzer R and Schumacher C: Glucocorticoid receptor antagonism by cyproterone acetate and RU486. Mol Pharmacol 63: 1012-1020, 2003.

33. Jenkins JL, Kao RY and Shapiro R: Virtual screening to enrich hit lists from high-throughput screening: a case study on smallmolecule inhibitors of angiogenin. Proteins 50: 81-93, 2003.

34. Kuntz ID: Structure-based strategies for drug design and discovery. Science 257: 1078-1082, 1992.

35. Rarey M, Kramer B, Lengauer T and Klebe G: A fast flexible docking method using an incremental construction algorithm. J Mol Biol 261: 470-489, 1996.

36. Yart A, Mayeux P and Raynal P: Gab1, SHP-2 and other novel regulators of Ras: targets for anticancer drug discovery? Curr Cancer Drug Targets 3: 177-192, 2003.

37. Muegge I and Martin YC: A general and fast scoring function for protein-ligand interactions: a simplified potential approach. J Med Chem 42: 791-804, 1999.

38. Sawada H, Nakagoshi M, Reinhardt RK, Ziegler I and Koch PB: Hormonal control of GTP cyclohydrolase I gene expression and enzyme activity during color pattern development in wings of Precis coenia. Insect Biochem Mol Biol 32: 609-615, 2002.

39. Jankun J and Skrzypczak-Jankun E: Molecular basis of specific inhibition of urokinase plasminogen activator by amiloride. Cancer Biochem Biophys 17: 109-123, 1999.

40. Zimmerman M, Quigley JP, Ashe B, Dorn C, Goldfarb R and Troll W: Direct fluorescent assay of urokinase and plasminogen activators of normal and malignant cells: kinetics and inhibitor profiles. Proc Natl Acad Sci USA 75: 750-753, 1978.

41. Huang SS and Zheng RL: Rosmarinic acid inhibits angiogenesis and its mechanism of action in vitro. Cancer Lett 2005, Oct 17 [Epub ahead of print]. 